\title{
4. How Boards and Senior Managers Have Governed
}

\author{
Raymond C Young, Department of Accounting and Finance, \\ Macquarie University
}

\begin{abstract}
This chapter positions IT project governance in the context of corporate governance and IT governance. It has highlighted dysfunctional behaviour and neglect of the governance perspective in project management practice and argued that the traditional measure of success 'on-time on-budget' is inappropriate for IT project governance. It presents a holistic framework of IT projects in the context of an organisation and lists six key IT project governance questions that should be asked by a board (or other approving authority), top managers and executive project sponsors. The detailed framework and questions are being published by Standards Australia as HB280 and they incorporate and extend the best of the IT project governance prescriptions that currently exist.
\end{abstract}

\section{How Boards and Senior Managers have governed ICT projects to succeed (or fail)}

Many boards are aware of the need for more guidance in the area of IT governance (Young and Jordan 2002). This is partly as a result of Sarbanes-Oxley and other international legislative responses to the spate of recent high profile corporate collapses (e.g. Enron, WorldCom, HIH, One-Tel, etc). It is also a reflection of a genuine desire of boards to improve their performance (Leblanc and Gillies 2005).

A number of good guidelines have been developed. These include a recent publication by CPA Australia (Gillies and Broadbent 2005), COBIT produced by the Information Systems Audit and Control Association COBIT 2000) and AS8015 produced by Standards Australia (AS8015 2005). However these guidelines are at focussed on IT governance as a whole and do not elaborate in any detail on how to govern IT projects. This distinction is important because 74 per cent of projects are undertaken as business improvement initiatives enabled by ICT (KPMG 2005) and belong more properly in the domain of corporate governance rather than being pure ICT projects within the domain of IT governance alone.

The objective of this chapter is to complete the picture by extending the IT Governance guidelines to describe how projects need to be governed at a board and senior management level. It summarises the findings of four years of research undertaken collaboratively with Standards Australia. This research has resulted 
in the award of a PhD thesis (Young 2005) and the findings are being published by Standards Australia as HB280, a handbook with the same title as this chapter.

\section{Success from a governance perspective}

A case study of an ERP implementation (Young 2005) highlights a paradox. The project is widely reported as a success because it was one of the world's fastest implementations of this particular ERP system. However, the benefits promised to the board were not realised. The business case stated that a minimum of $\$ 6$ million of benefits were to be delivered over five years and that the ERP would be upgraded to underpin the organisation's long term strategy. The project ended up delivering only $\$ 3$ million of benefits and the organisation lost confidence in its ability to realise benefits and deferred the upgrade indefinitely. The disappointment was compounded because management considered that they did everything right: they had formal governance structures (project sponsors, steering committee), formally documented and signed off individual responsibilities for each of the targeted benefits, followed a proper project management methodology, selected appointed a highly motivated high calibre project team, and they had the benefit of experienced consultants to guide the project.

The case study was titled 'how to fail successfully' because it was both a failure and a success depending on ones perspective. The problem it highlights is choosing which perspective to emphasise. Until now the IT vendors, IT professionals and project managers have had the loudest voices and they consciously or unconsciously dominate by abusing their so-called expertise (Thomsett 1989). By claiming to know what was wrong and assuring stakeholders the next technical solution would be the right one (Currie and Galliers 1999), for the last 20 years, the discussion of success has been confined largely to the issue of whether a project has come in on-time on-budget and whether it met specifications (Grindley 1995).

From a governance perspective this is wholly inappropriate. Governance is about both performance and risk (Standards Association of Australia 2003, Australian Stock Exchange 2003) and Hilmer captures the objectives well when he states that the objective is 'to ensure management is focussed on above average returns taking account of risk' (Hilmer 1993). Organisations do not invest in projects so that they can come in on-time on-budget or even to meet specifications! Projects are undertaken to realise benefits e.g. increased revenue, decreased costs, ability to respond faster to changing customer demands, etc. This governance perspective of whether a project is successful or not has been largely ignored. It has been overshadowed by the loud chorus of self interested vendors/professionals (wanting the next project) who claim projects were successes because technical objectives were met, users were satisfied or they came in on-time. A common practice is to choose success criteria only after a 
project has been implemented and to declare it to be a success based on whatever criteria of success has been met (Boddie 1987). In one perverse example a project team claimed a project was a success because they 'learned not to do that again'. Where is the governance voice asking 'where are the benefits you promised me?'

The pity of this situation is that many reputable people over the years have correctly pointed out why projects fail (Cooke-Davies 2002, Baccarini 1999, de Wit 1985, Markus et al 2000, Lucas 1975). They need to be heard because their perspective is consistent with good governance and they show quite clearly that achieving on-time on-budget or any of the lesser criteria for success (Delone and McLean 2003) does not strongly relate to the realisation of benefits. This has very important implications because the majority of IT prescriptions are focussed on how to do project management better or how to solve a technical issue. These prescriptions alone will not lead to success from a governance perspective; at best they will tend to lead to on-time on-budget. This is illustrated in Figure 1. Almost all the project advice that exists is focussed on the circled aspects of project management labelled 2-Planning, 3-Development or 4-Implementation (Yardley 2002). This advice has value but the emphasis at a governance level needs to be on clarifying what benefits are being targeted and whether they are being realised (i.e. 1-initiation and 5-benefit). There is very little guidance in this more important area, and what there is, tends to be directed at the project manager. This is wholly inappropriate because a project manager tends to leave at the end of a project, but the benefits of a project (IT projects in particular) tend to be realised some time after a project has been implemented, and is usually related to some degree of organisational change (Markus 1996). The implication is that for a guidance to be effective, it has to be directed at business managers, the owners of a project's outputs.

\section{Figure 1: Project Management success vs. Project success}

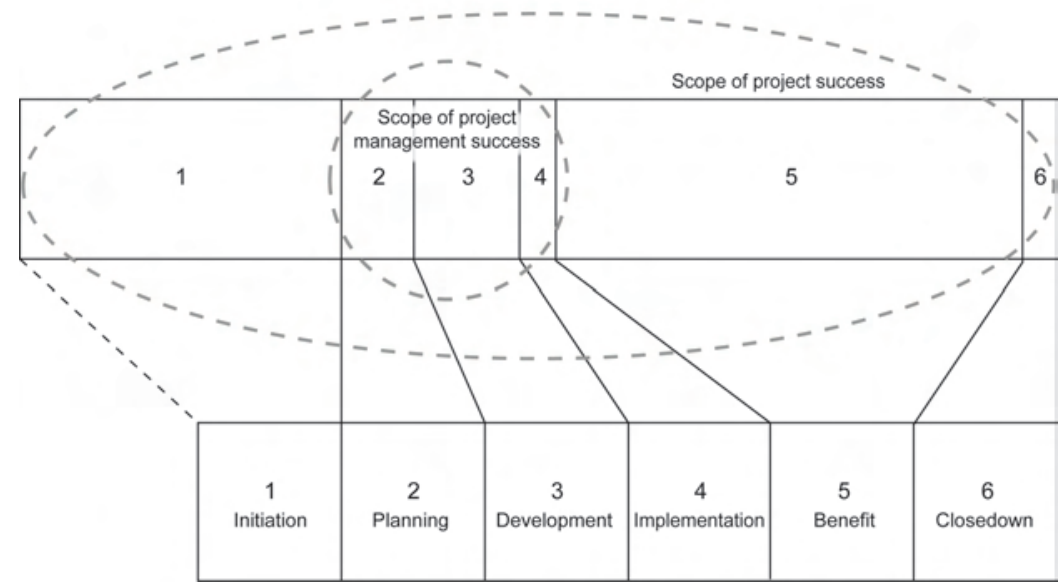


The final section will build on this discussion and present the best advice currently available for boards, top management and executive project sponsors. This audience has the largest impact on whether a project will succeed or fail (Young 2005) and is the right audience for any IT project governance guideline.

\section{How boards and top managers should govern projects}

The first half of this chapter has presented the evidence that projects can only be effectively governed when the most fundamental concepts are understood and accepted: (a) Projects are undertaken to realise some kind of organisational benefit, (b) benefits are seldom realised at the time of implementation and (c) benefits tend to be enabled by IT projects but tend only to be realised through accompanying organisational change. Project governance should therefore focus on clarifying what benefits are being targeted, what organisational changes need to be made to realise the benefits, whether the organisation has the capacity (and will) to make the necessary changes, and whether the benefits are being realised. Related to this is the issue of appointing a sponsor to be responsible for realising the benefits and choosing and implementing measure(s) to monitor on an ongoing basis whether the benefits are being realised.

This synthesis of the key aspects of project governance has been rigorously justified (Young 2005) and documented for the general public (Young, forthcoming). Considerations of length prevent a detailed explanation of the justification but it should be highlighted that it confirmed what has long been suspected Markus 1983), that top management support is the most important success factor. Project governance guidelines must therefore focus on top management responsibilities first. The existing prescriptions (e.g. project planning, project management, project staff, user involvement, etc.) do not need to be overly emphasised because they are already in widespread practice (Clegg et al 1997) and the failure statistics show quite clearly that they alone are not sufficient for success Young and Jordan 2005).

It should also be highlighted that the guidelines being presented in this chapter have taken into account all the relevant models of how IT projects deliver benefits (Yardley 2002, Akkermans and van Helden 2002, McGolpin and Ward 1997, Reich and Benbasat 1990, Soh and Markus 1995, Grover and Kettinger 2000, Markus 2000, Sharma and Yetton 2003) and well over 40 different prescriptions for top management support. What was found was that almost all the existing prescriptions focus on the 'hard' dimensions of governance (e.g. steering committees, governance processes, etc) and did not capture the essence of how top managers influenced projects to succeed. It was found that the 'soft' dimensions of governance (e.g. passion to drive change, belief in what is necessary, will to change, listening, communicating and influencing skills) were much more important and that they completely underpinned the effectiveness of whatever hard prescriptions were adopted. 


\section{HB280 \& AS8016}

The project governance advice to be presented therefore represents an attempt to summarise the best of what currently exists within a business/organisational framework (to overcome the deficiencies of the project-centric perspective). It is based partly on Australian Standard AS8015 on the corporate governance of ICT and it has informed the development of Australian Standard AS8016 on the corporate governance of ICT projects. It is more fully described in Standards Australia's handbook HB280.

The framework (Figure 2) shows that projects are undertaken to realise benefits by changing both ICT operations and business processes. It also shows that top management oversee or govern the change project. The framework identified six inter-related project governance activities that must be carried out by boards and top managers. These are:

1. Initiate

2. Evaluate

3. Support - motivation

4. Support - structure

5. Monitor - project

6. Monitor - benefits

\section{Figure 2: IT Project Governance Framework}

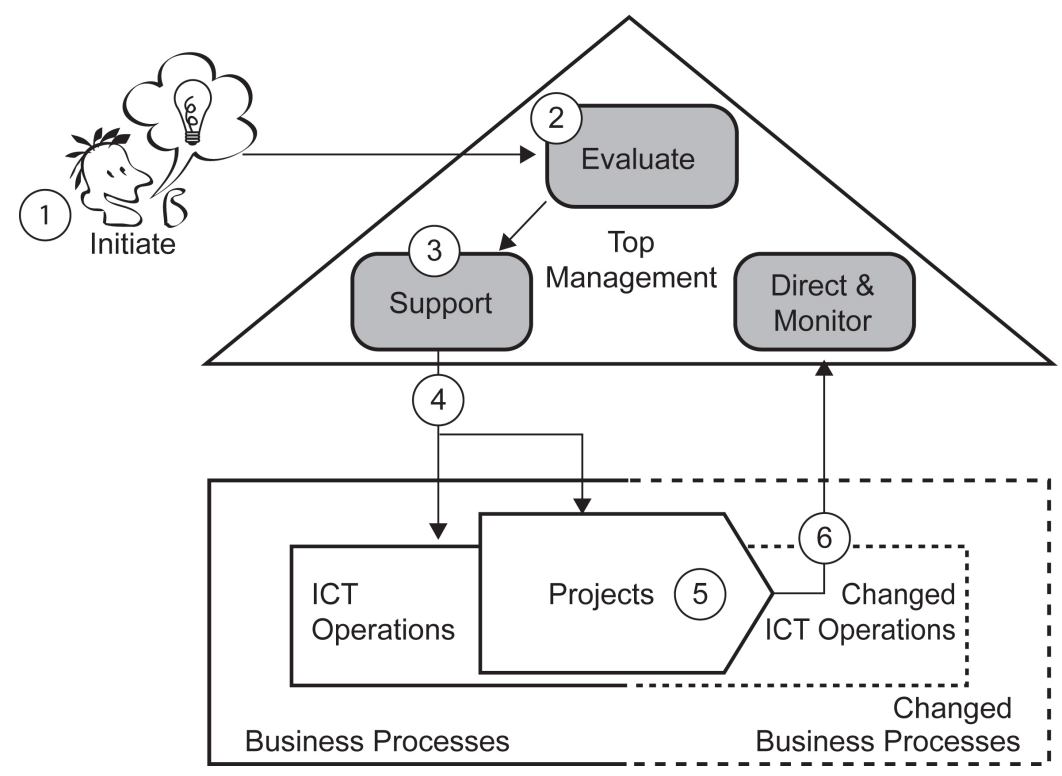




\section{Initiate \& Evaluate}

The initiate and evaluate stage is traditionally understood as the hard prescription 'to prepare and approve a business case'. A board or other approving authority needs to appreciate that the current practice often treats this process as a formal hurdle to be passed and that 70 per cent of approved business cases are predisposed to fail because they do not address the right governance issues (KPMG 2005).

What needs to be asked at the time of approval is 'What are the expected business benefits?' It must be determined at the outset whether there has been a thorough consideration of how a project contributes to a strategic objective and whether it contributes directly to an objective or whether it contributes to a program of projects which collectively contribute to one or more strategic objectives for an organisation. The approving authority should be very conscious of the tendency to write into a business case whatever words it takes to get funding without any real intention of delivering against the business case. They should be making the subjective assessment of whether the project sponsor genuinely believes in the objectives of the business case and has the passion to drive through the organisational changes needed to realise the promised benefits.

Related to this first question is the evaluation of risk. The greatest risk of any project is that it will fail to deliver the promised benefits (80-90 per cent likelihood of failure) so the key question should be 'How much organisational change is required to realise the benefits?' An approving authority needs to ensure this issue has been thoroughly considered and make the subjective assessment of whether their organisation has the will to make the changes needed to realise the benefits. There are also other risk considerations that should be part of the evaluation (e.g. economic feasibility, technical/operational feasibility, resourcing feasibility, etc), but these questions are really details to help answer the overall issue of how much risk is involved.

\section{Support}

The next key governance questions are based on an understanding of how much organisation change is required. Projects that cross more organisational boundaries and require more organisational change are much more difficult because of the larger number of often very powerful stakeholders involved. The approving authority needs to assess 'Who should sponsor the project' (on their behalf and be responsible for delivering the promised benefits)? The sponsor needs not only the passion to drive through the changes, but also the ability, authority and influencing skills to make it happen. In some cases only the CEO is the right sponsor, but an alternative arrangement may need to be made because the CEO may not have enough time to govern all aspects of the project. Quite often this will relate to the reward mechanism that is adopted. 
The underlying issue is how to motivate the stakeholders and in particular the sponsor to deliver the promised benefits. Historically projects have not been measured or only measured on the basis of on-time on-budget. This is not sufficient for effective project governance and an approving authority needs to specifically ask the question 'How will the benefits be measured and sponsor rewarded?' In some organisational cultures, performance bonuses are appropriate, in other cultures it may be appropriate to revise the sponsor and other stakeholder's budget to reflect the business case promises, in other cases it might be enough to focus attention by implementing a regularly reviewed board level progress report. The answer to this question should probably be proposed in the business case and it is important for the board to consider whether it is likely to influence stakeholders appropriately given the history of dysfunctional behaviour in the project space. It is almost never appropriate to monitor solely on the basis of on-time on-budget and it is incumbent on the board to insist on a more meaningful measure of success, a measure that is more directly related to the business case benefits.

\section{Direct \& Monitor}

Once a project has been approved and funded, monitoring occurs at two levels. At the project level, the sponsor monitors on behalf of the board to ensure risk is being managed. At the organisational level the board monitors the sponsor to ensure (s)he is focussed on realising the promised benefits. The board must oversee some mechanism to monitor the sponsor because it would be a clear conflict of interest to have the sponsor monitor themselves. It would expose the organisation to the risk of having the sponsor change the success criteria if the project fails to deliver what was originally promised. This is the current practice and can probably only be overcome with this additional board level discipline. The advantage of having this mechanism is not that targets will cease to change, but that boards will have earlier warning and have more opportunities to cancel projects if circumstances change and make projects unviable. A board must have the discipline to intercede and cancel unviable projects because it is too much to expect a fired-up project sponsor to be objective enough to cancel his own project. The key governance question at an organisational level is 'Are the benefits on target or being realised?' This cannot be answered without some kind of monitoring mechanism (ref Q3) and related to this is the question of whether appropriate interventions are being directed if the benefits are not on target.

Monitoring at a project level is generally not the direct responsibility of the board. This activity can be performed on their behalf by the project sponsor and can be thought of as risk management. The main mechanism for risk management is the preparation of a project plan to manage all the expected risks. Project plans are usually well done by following existing project management 
guidelines. However, project plans do not plan for unanticipated risks and the majority of projects need to be changed as these unanticipated risks arise (Dvir and Lechler 2004). There is almost always a warning signal (Nikander and Eloranta 2001) and the key from a governance perspective is to ensure the project culture encourages stakeholders at any level to raise issues that may compromise the targeted benefits. This requires at one level a clear understanding by all the stakeholders of what the targeted benefits are, and at another level the willingness to listen and explore the business impact of issues as they are raised. It is particularly difficult with IT projects because the connection between technical issues and business outcomes is often not immediately apparent when they are first raised. The right culture seems to require a sensitivity and humility (willingness to learn) on the part of all stakeholders and in particular on the part of the executive project sponsor, because they set the tone for what will be addressed and what will not. This has many parallels with what is referred to as establishing a whistle-blowing culture within the corporate governance literature (Near and Miceli 1995, Smith and Keil 2003). Once a project has been commenced by following the traditional project management guidelines, the key governance question is "Is the culture right for unexpected issues to be raised?"

\section{Conclusion}

This chapter has positioned IT project governance in the context of corporate governance and IT governance. It has highlighted dysfunctional behaviour and neglect of the governance perspective in project management practice over the last 40 years. It has shown that a fundamental part of the solution is to recognise that projects are undertaken to realise some organisational benefit and recognise that these benefits are usually delivered some time after a project has been implemented. This insight was extended to show that benefits are delivered mainly by operational management rather than project management and that the proper audience for IT project governance includes operational managers, board members and top managers in particular.

The chapter argues that the traditional measure of success 'on-time on-budget' is inappropriate for IT project governance. It presents a holistic framework of IT projects in the context of an organisation and lists six key IT project governance questions that should be asked by a board (or other approving authority), top managers and executive project sponsors. The framework and questions are being published by Standards Australia as HB280 and they incorporate and extend the best of the IT project governance prescriptions that currently exist.

Six key IT project governance questions are presented, corresponding to different parts of a project lifecycle. 
1. What are the expected benefits?

2. How much change is required to realise the benefits?

3. How will the benefits be measured and the sponsor rewarded?

4. Who should sponsor the project?

5. Are the benefits being realised?

6. Is the culture right for unexpected issues to be raised?

\section{References}

Akkermans, $\mathrm{H}$ and $\mathrm{K}$ van Helden 2002, 'Vicious and virtuous cycles in ERP implementation: A case study of interrelations between critical success factors', European Journal of Information Systems, 11(1), p. 35-46.

Australian Stock Exchange 2003, ASX, Principles of Good Corporate Governance and Best Practice Recommendations, Sydney.

Baccarini, D 1999, 'The Logical Framework for Defining Project Success', Project Management Journal, 30(4), p. 25-32.

Boddie, J 1987, 'The Project Post-Mortem', Computerworld, 21(49), p. 77-82.

Clegg, C et al 1997, 'Information Technology: A study of performance and the role of human and organizational factors', Ergonomics, 40(9), p. 851-871.

COBIT, Framework 2000, IT Governance Institute, Rolling Meadows.

Cooke-Davies, T 2002, 'The "Real" Success Factors on Projects', International Journal of Project Management, 2002, 20, p. 185-190.

Currie, W. and B. Galliers eds. 1999, Rethinking Management Information Systems, Oxford University Press, New York.

de Wit, A 1985, 'Measurement of Project Success', International Journal of Project Management, 6(3), p. 164-170.

Delone, W.H. and E.R. McLean, 2003, 'The Delone and McLean Model of Information Systems Success: A ten-year update', Journal of Management Information Systems, 19(4), p. 9-30.

Dvir, D. and T. Lechler, 2004, 'Plans are Nothing, Changing Plans is Everything: The impact of changes on project success', Research Policy, 33: p. 1-15.

Gillies, C and M Broadbent eds. 2005, IT Governance: A Practical Guide for Company Directors and Corporate Executives, CPA Australia.

Grindley, K 1995, Managing IT at Board Level: The hidden agenda exposed, 2nd edition, London, Pitman.

Grover, V and WJ Kettinger 2000, 'Business Process Change: A reflective view of theory, practice, and implications', in Framing the Domains of IT Management: Projecting the Future Through the Past, RW Zmud (ed.), Pinnaflex Educational Resources, Cincinnati, Ohio,. pp 147-172, 433-435. 
Hilmer, FG 1993, Strictly Boardroom: Improving governance to enhance company performance, The Business Library, Melbourne.

KPMG 2005, Global IT Project Management Survey: How committed are you?, KPMG.

Leblanc, $\mathrm{R}$ and $\mathrm{J}$ Gillies 2005, Inside the Boardroom: The coming revolution in corporate governance, John Wiley and Sons, Toronto.

Lucas, HC 1975, Why Information Systems Fail, Columbia University Press, New York.

Markus, LM 2000, 'Toward an integrated theory of IT related risk control in IFIP TC8 WG8.2', International Working Conference on the Social and Organizational Perspective on Research and Practice in Information Technology, Kluwer Aalborg, Denmark.

Markus, LM 1996, 'Change Agentry - The next IS frontier', MIS Quarterly, Dec., p. 385-407.

Markus, LM 1983, 'Power, Politics, and MIS Implementation', Communications of the ACM, 28(6), p 430-444.

Markus, ML et al 2000, 'Learning from Adopters' Experience with ERP: Problems encountered and success achieved', Journal of Information Technology, 15, p. 245-265.

McGolpin, P and J Ward 1997, 'Factors Influencing the Success of Strategic Information Systems', in Information Systems: an emerging discipline?, J Mingers and F Stowell (Eds.), McGraw-Hill: London. p. 287-327.

Near, JP and MP Miceli 1995, 'Effective Whistle-Blowing', Academy of Management Review, 20(3), p. 679-707.

Nikander, IO and E Eloranta 2001, 'Project Management by Early Warnings', International Journal of Project Management, 19, p. 385-399.

Reich, BH and I Benbasat 1990, 'An Empirical Investigation of Factors Influencing the Success of Customer-Oriented Strategic Systems', Information Systems Research, 1(3), p 325-347.

Sharma, R and P Yetton 2003, 'The Contingent Effects of Management Support and Task Interdependence on Successful Information Systems Implementation', MIS Quarterly, 27(4), p 533-555.

Smith, HJ and M Keil 2003, 'The Reluctance to Report Bad News on Troubled Software Projects: A theoretical model', Information Systems Journal, 13(1), p. 69-95.

Soh, C and ML Markus1995, 'How IT Creates Business Value: A Process Theory Synthesis', in the Sixteenth International Conference on Information Systems. Amsterdam, The Netherlands. 
Standards Association of Australia 2005, AS8015, Corporate Governance of Information and Communication Technology, Sydney.

Standards Association of Australia (forthcoming), HB 280, Case Studies - How boards and senior management have governed ICT projects to succeed (or fail), $\mathrm{R}$ Young, (ed.), Sydney.

Standards Association of Australia 2003, AS8000, Corporate Governance - Good Governance Principles, Sydney.

Thomsett, R 1989, Third Wave Project Management, Prentice-Hall, Englewood Cliffs.

Yardley, D 2002, Successful IT Project Delivery: Learning the lessons of project failure, Addison-Wesley, London.

Young, R and E Jordan 2005, 'The Implications of Australian ICT Governance Standards for COBIT', in 2005 IT Governance International Conference, Auckland, New Zealand.

Young, R 2005, 'Case 2005-2: How Projects Fail "Successfully", Macquarie Graduate School of Management, Macquarie University, Sydney, Australia.

Young, R 2005, 'Explaining Senior Management Support Through IT Project Governance', in MGSM, Macquarie University, Sydney.

Young, RC and E Jordan 2002, 'Lifting the Game: Board views on e-commerce risk', in IFIP TG8.6 the Adoption and Diffusion of IT in an Environment of Critical Change, Sydney, Pearson Publishing Service. 